\title{
Early diagnosis of diabetic nephropathy using spot urine microalbumin in type 2 diabetes mellitus patients
}

\author{
Ketham Veera Sudhakar ${ }^{1}$, B Ravindra Reddy ${ }^{2 *}$, J Dinesh ${ }^{3}$ \\ 1,2Assistant professor, 3Professor and HOD, Department of Biochemistry, Viswabharathi medical college and general hospital, R.T nagar, \\ Near penchikalapadu, Kurnool-518463, Andhra Pradesh, INDIA. \\ Email: bobre123@gmail.com
}

$\underline{\text { Abstract }}$

\begin{abstract}
Background: The studies using newer diagnostic methods to detect urinary albumin excretion (UAE) sub-clinically have given hopes of detecting early nephropathy and possible intervention to retard or reverse nephropathy at that stage. The present study is carried out to assess $\mathrm{HbAlc}$, lipid profile and urine microalbumin in type 2 diabetic patients. Material and methods: The present study was carried out on 30 type 2 diabetic patients, and 30 normal healthy controls included both males and females in the age group of 30 years to 70 years from government General hospital, Kurnool. Results: The urinary microalbumin, total cholesterol, triglycerides, HDL, VLDL, and LDL in diabetic cases are in the range of $94.10 \pm 12.80 \mathrm{mg} / \mathrm{l}, 193.4 \pm 10.73 \mathrm{mg} / \mathrm{dL}, 196.6 \pm 18.26 \mathrm{mg} / \mathrm{dL}, 34.4 \pm 3.6 \mathrm{mg} / \mathrm{dL}, 39.3 \pm 2.5 \mathrm{mg} / \mathrm{dL}, 119.6 \square 11.5 \mathrm{mg} / \mathrm{dL}$ respectively and in controls are in the range of $18.86 \pm 1.50 \mathrm{mg} / 1,164 \pm 6.5 \mathrm{mg} / \mathrm{dL}, 135.86 \pm 10.80 \mathrm{mg} / \mathrm{dL}, 46.6 \pm 4.2 \mathrm{mg} / \mathrm{dL}$, $27.16 \pm 2.29 \mathrm{mg} / \mathrm{dL}, 91.1 \pm 7.26 \mathrm{mg} / \mathrm{dL}$ respectively were increased in diabetic cases when compared to controls, whereas HDL is decreased in diabetic cases when compared to controls. The increase is highly significant for urinary microalbumin, Lipid profile values $(\mathrm{P}<0.001$ and $\mathrm{P}<0.001)$ and decrease is significant for HDL $(\mathrm{P}<0.001)$, and there was a positive correlation between triglyceride and urine microalbumin. Conclusion: Microalbuminuria in type 2 diabetic patients is associated with hyperlipidemia may represent a risk factor for cardiovascular disease and may contribute to the progression of renal disease and early detection and treatment prevent development of end stage renal disease.
\end{abstract}

Key Word: Cardiovascular disease, Diabetic nephropathy, Lipid profile, and Micro albuminuria.

\section{*Address for Correspondence:}

Dr. B. Ravindra Reddy, Assistant Professor, Department of Biochemistry, Viswabharathi Medical College and General Hospital, R.T Nagar, Near penchikalapadu, Kurnool-518463, INDIA.

Email: bobre123@ gmail.com

Received Date: 16/09/2018 Revised Date: 23/10/2018 Accepted Date: 08/11/2018

DOI: https://doi.org/10.26611/1002911

\begin{tabular}{|l|l|}
\hline \multicolumn{2}{|c|}{ Access this article online } \\
\hline Quick Response Code: & Website: \\
\hline & www.medpulse.in \\
\cline { 2 - 2 } & \\
\hline
\end{tabular}

\section{INTRODUCTION}

Approximately $20 \%$ to $30 \%$ of patients with type $1 \mathrm{DM}$ will have Microalbuminuria after a mean duration of diabetes of 15 years and less than half of these patients will progress to Microalbuminuria which also called overt nephropathy (1-3). After overt nephropathy development, the substantial number of patients will progress to endstage renal disease (ESRD) with reported rates of $4 \%$ to $17 \%$ at 20 years and approximately $16 \%$ at 30 years from time of initial diagnosis of $\mathrm{DM}^{4,5}$. Microalbuminuria is increased albumin creatinine ratio (ACR) (or) Increased albumin excretion rate in at least 2 out of 3 samples collected in the absence of infection or an acute metabolic crisis. Conditions in which Microalbuminuria commonly occurs in Renal disorders, Diabetes Mellitus, Preeclampsia, Immune related disorders, Reactions to nephrotoxic drugs, Renal transplant, Surgery, Anaesthesia, Hypertension, Atherosclerosis and infarction. The pathophysiology underlying microalbuminuria is believed to include 2 major classes 
of factors are Elevation in intra glomerular pressure, and Structural or functional changes of the mesangium and the glomerular basement membrane ${ }^{6}$. Microalbuminuria can be diagnosed from a 24 hour urine collection (between $30-300 \mathrm{mg} / 24$ hours) or more commonly from elevated concentrations in a spot sample $(30-300 \mathrm{mg} / \mathrm{L})$.
The significance of microalbuminuria is that it is an early index of diabetic nephropathy and also index of cardiovascular morbidity and mortality in non-insulin dependent diabetes mellitus. ${ }^{6}$. Untreated microalbuminuria in type- 2 diabetes mellitus, progresses to overt diabetic nephropathy.

Stage of Diabetic Nephropathy:

\begin{tabular}{|c|c|}
\hline Stage & Characteristics \\
\hline Normoalbuminuria & Urinary albumin excretion no rmal. (<20ng/min). \\
\hline M icroalbuminuria Incipient nephropathy. & $\begin{array}{c}\text { UAE increases 20-200 } \mu \mathrm{g} / \mathrm{min} \text {. Persistent microalbuminuria, hyperfiltration, BP } \\
\text { elevation }\end{array}$ \\
\hline Early overt diabetic nephropathy & $\begin{array}{c}\text { Clinical proteinuria (UAE > } 200 \mathrm{ng} / \mathrm{min} \text { in two out of } 3 \text { measurements with in } 6 \\
\text { months or dip stick positive proteinuria), hypertension. }\end{array}$ \\
\hline Advanced diabetic nephropathy & $\begin{array}{c}\text { Progressive Proteinuria, hypertension, Declining glo merular filtration rate } \\
\text { (decreased creatinine clearance). }\end{array}$ \\
\hline ESRD & Uraemia, NS, need for renal, Replacement Therapy (Transplantation or dialysis). \\
\hline
\end{tabular}

Patients of diabetes mellitus are at greatest risk for microvascular complications such as nephropathy, retinopathy and peripheral neuropathy and macrovascular complications. Clinical proteinuria has commonly been detected by dipstick measurement. Microalbuminuria refers to a urinary albumin concentration below the level detected by dipsticks ${ }^{7}$. Increased intraglomerular pressure may be caused by an imbalance in afferent and efferent renal vascular tone, increased blood flow and extracellular fluid volume. Together, elevated hydrostatic and oncotic pressures initially cause renal hyper filtration, mesangial hypertrophy and proliferation, as well as changes in the polyanionic charge and porosity of the glomerular basement membrane in the kidney and in other vascular sites (eg. retina, arteries, nerve) by deposition of advanced glycation end products. Perhaps the most studied marker of diabetes mellitus and diabetes related complication is microalbuminuria. In Diabetes Mellitus, microalbuminuria develops in $20-40 \%$ of both IDDM and NIDDM patients. The underlying physiology of microalbuminuria and its effect on clinical outcome in diabetes mellitus is unclear. However, persistent microalbuminuria may reflect a systemic, endothelial and vascular disorder rather than reflect only glomerular structural abnormalities ${ }^{8}$. The present study is carried out to assess $\mathrm{HbA} 1 \mathrm{c}$, lipid profile and urine microalbumin in Type 2 diabetic patients.

\section{MATERIALS AND METHODS}

Study design: Prospective case control study was conducted.
Setting: This study was conducted at Biochemistry department with collaboration with Nephrology department. We included A total of 60 (30 type 2 diabetic patients, and 30 healthy controls) age and sex matched subjects were participated in the study by giving informed consent form from government General hospital, Kurnool. Patients with chronic renal failure, glomerular nephritis due to other systemic conditions and hypertensives were excluded from the study.

Sample collection and analysis: After an overnight fast of 12 to $14 \mathrm{hrs}, 5 \mathrm{ml}$ blood was collected by venipuncture. $2 \mathrm{ml}$ of blood was collected in anticoagulant (EDTA and fluoride) vacutainer. The remaining $3 \mathrm{ml}$ is taken into another test tube and allowed to clot. Serum and plasma were separated. The fasting blood sugar by GOD-POD method and Glycated Hemoglobin by Micro column method on RA-50 instrument, Lipid profile was estimated and patient is given a clean container without preservative and early morning mid stream urine sample $(10 \mathrm{ml})$ was collected.

Selection of cases for microalbumin test: Type 2 diabetic patients (NIDDM) were screened for overt proteinuria by strip Test. Those cases which were negative for Strip test were taken up for microalbumin study.

Statistical analysis: All values obtained will be expressed as Mean ( \pm SEM). Unpaired two-tailed student $t$-test will be performed to compare the difference in the means between controls and study group. A ' $\mathrm{P}$ ' value $<0.05$ will be considered as statistically significant. Statistical Analysis will be done by using Microsoft excel spread sheets. 


\section{RESULTS}

A total number of 60 subjects, 30 healthy controls (Males: 18, and Females: 12) and 30 cases (Type 2 diabetic patients: Males: 19, and Females: 11) were include in the study.

Table1: shows comparison of fasting bloo d gluco se, Glycosylated haemoglobin (HbAlc), Urinary microalbumin, Lipid pro file in between cases and controls.

\begin{tabular}{|c|c|c|c|c|c|}
\hline & & Cases & Control & Tvalue & P value \\
\hline \multirow{2}{*}{ FBS } & Mean & 182.433 & 92.7667 & \multirow{2}{*}{34.3082} & \multirow{2}{*}{$\varangle 0.001 \mathrm{~S}$} \\
\hline & SD & 13.6298 & 4.37614 & & \\
\hline \multirow{2}{*}{$\mathrm{HBA}_{1 \mathrm{C}}$} & Mean & 9.04333 & 5.95333 & \multirow{2}{*}{12.5658} & \multirow{2}{*}{$\varangle 0.001 \mathrm{~S}$} \\
\hline & SD & 1.3395 & 0.14077 & & \\
\hline \multirow{2}{*}{ UMA } & Mean & 94.1 & 18.8667 & \multirow{2}{*}{12.5481} & \multirow{2}{*}{$\varangle .001 \mathrm{~S}$} \\
\hline & SD & 12.8049 & 1.50249 & & \\
\hline \multirow{2}{*}{ TC } & Mean & 193.46 & 164.86 & \multirow{2}{*}{12.43} & \multirow{2}{*}{$\varangle 0.001 \mathrm{~s}$} \\
\hline & SD & 10.73 & 6.59 & & \\
\hline \multirow{2}{*}{ TG } & Mean & 196.63 & 135.86 & \multirow{2}{*}{15.68} & \multirow{2}{*}{$\varangle 0.001 \mathrm{~S}$} \\
\hline & SD & 18.26 & 10.8 & & \\
\hline \multirow{2}{*}{$\mathrm{HDL}$} & Mean & 34.46 & 46.6 & \multirow{2}{*}{12.61} & \multirow{2}{*}{$\varangle 0.001 \mathrm{~S}$} \\
\hline & SD & 3.66 & 4.28 & & \\
\hline \multirow{2}{*}{ VDL } & Mean & 39.33 & 27.16 & \multirow{2}{*}{15.54} & \multirow{2}{*}{$\varangle 0.001 \mathrm{~S}$} \\
\hline & SD & 2.53 & 2.22 & & \\
\hline \multirow{2}{*}{$L D L$} & Mean & 119.6 & 91.1 & \multirow{2}{*}{11.42} & \multirow{2}{*}{$\varangle 0.001 \mathrm{~S}$} \\
\hline & SD & 11.57 & 7.26 & & \\
\hline
\end{tabular}

Table 2: shows the correlation between the various parameters

\begin{tabular}{lllllll}
\hline & & HbAlc & T.Ch & TG & HDL-C & U.M.A \\
\hline \multirow{2}{*}{ FBS } & r & 0.202 & 0.139 & 0.089 & -0.160 & 0.233 \\
& P & 0.001 & 0.001 & 0.001 & 0.001 & 0.001 \\
HbAlc & $r$ & & & 0.35793 & 0.1538 & 0.03571 \\
& $P$ & & & 0.001 & 0.001 & 0.001 \\
Triglyceride & $\mathrm{r}$ & & & & & 0.10521 \\
& $\mathrm{P}$ & & & & & 0.001 \\
\hline
\end{tabular}

\section{DISCUSSION}

In the present study we considered 60 subjects, including 30 T2DM patients and 30 controls. We estimated HbA1c, lipid profile and urinary microalbumin in random urine sample. There was a significant increase in the FBS levels and $\mathrm{HbA} 1 \mathrm{c}$ levels in diabetic patients when compared to the control group. The mean FBS level in diabetic patients was $182.4 \pm 13.62 \mathrm{mg} / \mathrm{dl}$, and in the controls, it was $92.76 \pm 4.37 \mathrm{mg} / \mathrm{dl}$. Our findings are comparable with the previous studies done by Meigs jb et $a l^{9}$, who have found that there was a significant association between FBS levels with the severity of diabetic nephropathy. The mean $\mathrm{HbA1}$ c levels in diabetic patients were 9.043 \pm 1.33 $\%$ and in the controls, it was $5.95 \pm 0.14 \%$. Our findings are comparable with the previous studies done by" Nathan DM et al, ${ }^{10}$ who have observed increased HbA1c levels in diabetic patients when compared to the control group. Studies have also shown that in patients with type 2 diabetes mellitus, every $1 \%$ increase in HbAlc would result in an increase in the micro vascular complications (such as diabetic nephropathy) by $37 \%$. The findings of the present study and the previous studies show that hyperglycemia, as indicated by the increase in the FBS and $\mathrm{HbA} 1 \mathrm{c}$ levels, is a potent predictor of progression of diabetic nephropathy. The possible mechanism is hyperglycemia leads to glycation of virtually all proteins, resulting in the formation of advanced glycation end products. These advanced glycation end products induce cross linking of collagen and other extracellular matrix proteins in many tissues including arterial vessel walls. Hyperglycemia-induced vascular injury leads to increased glucose flux through the polyol pathway, resulting in cellular damage, thereby resulting in the various micro vascular and macro vascular complications. HbA1c is also shown to have a special affinity for oxygen thereby causes tissue anoxia and plays a role in causation of micro and macroangiopathy. The interaction of advanced glycation end products and their receptors have been implicated as mediators of micro vascular permeability, ischemia and angiogenesis. In the present study the mean total cholesterol level in diabetic cases was $193.4 \pm 10.73$ $\mathrm{mg} / \mathrm{dL}$ and in controls it was $164 \pm 6.5 \mathrm{mg} / \mathrm{dL}$. In the present study serum total cholesterol levels corresponds to observations made by Mogensen et. al, ${ }^{11}$ in diabetic 
nephropathy patients. The mean triglyceride level in diabetic patients was $196.6 \pm 18.26 \mathrm{mg} / \mathrm{dL}$, and in controls it was $135.86 \pm 10.80 \mathrm{mg} / \mathrm{dL}$, this increased triglyceride values were comparable with study done by Magda.S et $a l,{ }^{12}$ and Cederholm et al, ${ }^{13}$ in diabetic nephropathy patients when compared to control group. In the present study, the mean microalbumin levels in urine, in diabetic patients was $94.10 \pm 12.80 \mathrm{mg} / \mathrm{l}$ and in the control group it was $18.86 \pm 1.50 \mathrm{mg} / \mathrm{l}$. There was a significant increase in the microalbumin levels in urine in diabetic patients when compared to the control group. The findings of the present study and the previous studies show that microalbuminuria is strongly related to the degree of hyperglycemia, which leads to the formation of advanced glycation end products. These advanced glycation end products result in the various micro vascular complications. In the present study, we found that there was statistically significant correlation between the various parameters i.e., FBS, $\mathrm{HbAlc}$, total cholesterol, triglyceride, and microalbuminuria. We found positive correlation microalbuminuria with FBS, $\mathrm{HbA1c}$, total cholesterol, and triglyceride. Our findings are comparable with previous studies done by Meig jb et.al, ${ }^{9}$ Nathan DM et al,${ }^{10}$ that the poor control of blood sugar and microalbuminuria increase the risk for the development of nephropathy. Early diagnosis and prompt treatment in these patients can reduce the onset and progression of nephropathy.

\section{CONCLUSION}

Microalbuminuria in T2DM patients is associated with hyper lipidemia. This association may represent a risk factor for cardiovascular disease and may contribute to the progression of renal disease. Early detection and treatment of diabetic nephropathy prevent development of end stage renal disease which is a major cause of morbidity and mortality in diabetic patients, and also improve the quality of life and increase life expectancy.

\section{REFERENCES}

1. Ritz E, Orth SR. Nephropathy in patients with type 2 diabetes mellitus. N Engl J Med. 1999; 341: 1127.
2. Lewis EJ, Hunsicker LG, Clarke WR, Berl T, Pohl MA, Lewis JB. et al. Renoprotective effect of the angiotensinreceptor antagonist irbesartan in patients with nephropathy due to type 2 diabetes. N Engl J Med. 2001; 345: 851-60.

3. Brenner BM, Cooper ME, de Zeeuw D, Keane WF, Mitch WE, Parving HH. et al. Effects of losartan on renal and cardiovascular outcomes in patients with type 2 diabetes and nephropathy. N Engl J Med. 2001; 345: 861-9.

4. Ritz E, Orth SR. Nephropathy in patients with type 2 diabetes mellitus. N Engl J Med. 1999; 341: 1127.

5. Krolewski M, Eggers PW, Warram JH. Magnitude of end-stage renal disease in IDDM: a 35 year follow-up study. Kidney Int. 1996; 50: 2041.

6. Ki-Chul Sung, Seungho Ryu, Jong-Young Lee, Sung Ho Lee, EunSun Cheong, Young-Youl Hyun, et.al,. Urine Albumin/Creatinine Ratio Below $30 \mathrm{mg} / \mathrm{g}$ is a Predictor of Incident Hypertension and Cardiovascular Mortality. J Am Heart Assoc. 2016; 5(9): e003245.

7. Aastha Chawla, Rajeev Chawla, Shalini Jaggi. Microvasular and macrovascular complications in diabetes mellitus: Distinct or continuum? Indian J Endocrinol Metab. 2016; 20(4): 546-51.

8. Selim Fakhruddin, Wael Alanazi, Keith E. Jackson. Diabetes-Induced Reactive Oxygen Species: Mechanism of Their Generation and Role in Renal Injury. J Diabetes Res. 2017.

9. Meigs JB, Mittleman MA, Nathan DM, Tofler GH, Singer DE, Murphy-Sheehy PM, et.al,. Hyperinsulinemia, hyperglycemia, and impaired hemostasis: the Framingham Offspring Study. JAMA. 2000; 283(2):221-8.

10. Nathan DM, Singer DE, Hurxthal K, Goodson JD. The clinical information value of the glycosylated haemoglobin assay. N. Engl J Med. 1984; 310: 341-6.

11. Mogensen C.E., Christensen CK. Predicting diabetic nephropathy in insulin dependent patients. N. Engl J. Med. 1084; 311: 89-93.

12. Magda S. Perassolo, Jussara C. Almeida, Ronivan L. Prá, Vanessa D. Mello, Ana L. Maia, Cileide C. Moulin, et. al. Fatty Acid Composition of Serum Lipid Fractions in Type 2 Diabetic Patients With Microalbuminuria. Diabetes Care 2003; 26(3): 613-8.

13. Cederholm J, Eliasson B, Nilsson PM, Weiss L, Gudbjörnsdottir S Steering Committee of the Swedish National Diabetes Register. Microalbuminuria and risk factors in type 1 and type 2 diabetic patients. Diabetes Res Clin Pract. 2005; 67: 258-66.

Source of Support: None Declared Conflict of Interest: None Declared 